\title{
'Kanga Kibao' celebrates the power and poetry of the kanga cloth in East Africa
}

\section{News}

29 March 2017-Stone Town, Zanzibar-In partnership with Upendo Women's Empowerment and Jalada Mobile Literary Festival, a pan-African group of writers on a 12-city, 5-country literary tour of East Africa, The Kanga Book presented 'Kanga Kibao,' a one-day exhibition celebrating the literary and cultural significance of the kanga cloth in East Africa.

Alessia Lombardo, manager of Upendo Women's Empowerment, explained, "The Kanga Kibao exhibition fits perfectly with Upendo's mission to empower women. The kanga speaks for and about women's lives."

Over 100 guests attended the exhibit throughout the day, marveling 29 kanga designs currently on the market that feature the most compelling 'majina' or 'names' written in bold capital letters at the bottom of the cloth just above the 'pindo' or border. The exhibit highlighted the pleasure of 'mafumbo' or 'ambiguous text' like the popular 'Mchungulia Bahari Si Msafiri' which means 'She who peeks at the sea is not a traveler.' With layered meanings, kanga sayings challenge the reader to contemplate the complexities.

The exhibit design is inspired by the iconic image of the kanga cloth drying on the laundry line in the hot sun with their messages swaying in the wind.

As part of the exhibition, The Kanga Book organized a guest talk by Farouque Abdela, a well-known Zanzibari fashion designer, who showcased some of the oldest kanga in his collection, and discussed the myriad ways in which kanga appear in everyday social, political, cultural, and religious life in Zanzibar.

Later in the afternoon, 40 girls and women participated in a writing workshop and discussion exploring 'women's stories about kanga' and 'kanga stories about women.' Participants brought a kanga from
Volume I Issue 3 - 2017

\author{
Amanda Leigh Lichtenstein \\ Resident Director of a Swahili Overseas Flagship Program, State \\ University of Zanzibar, Tanzania
}

\begin{abstract}
Correspondence: Amanda Leigh Lichtenstein, Resident Director of a Swahili Overseas Flagship Program, State University of Zanzibar, Tanzania, Email alichtenstein@gmail.com
\end{abstract}

Received: March 29, 2017 | Published: April 05, 2017

their own collection or selected a kanga from the exhibition to spark dialogue on themes such as love, jealousy, and forgiveness. They also composed original kanga sayings such as 'Don't Wait, Speak of Your Love Now, Or Forever Be Silent,' and 'Bahati Ni Kusafiri Na Wewe' which means 'Luck is Traveling with You.'

The Kanga Kibao exhibition will follow the Jalada Africa writers to Mombasa, Kenya, their last stop on their 12-city literary tour.

While Tanzania and Zanzibar continues to change, the kanga remains a steadfast cultural thread woven through the fabric of Swahili coastal life.

\section{Acknowledgments}

None.

\section{Conflict of interest}

Author declares there is no conflict of interest in publishing the article. 